\title{
Molecular Simulation Studies of Flue Gas Purification by Bio-MOF
}

\author{
Zhi Li ${ }^{1,2}$, Gangqiang Xu ${ }^{2}$, Bei Liu ${ }^{1,2, *}$, Xin Lv ${ }^{1}$, Guangjin Chen ${ }^{2}$, Changyu Sun ${ }^{2}$, Peng Xiao ${ }^{2}$ \\ and Yifei Sun ${ }^{2}$
}

1 State Key Laboratory of Offshore Oil Exploitation, Beijing 100027, China;

E-Mails: 1z979157903@163.com (Z.L.); 1vxin@cnooc.com.cn (X.L.)

2 State Key Laboratory of Heavy Oil Processing, China University of Petroleum, Beijing 102249,

China; E-Mails: xugangqiang2014@163.com (G.X.); gjchen@cup.edu.cn (G.C.);

cysun@cup.edu.cn (C.S.); xpmail@yeah.net (P.X.); 13261688985@163.com (Y.S.)

* Author to whom correspondence should be addressed; E-Mail: liub@cup.edu.cn;

Tel.: +86-10-8973-3252; Fax: +86-10-8973-2126.

Academic Editor: Mehrdad Massoudi

Received: 4 August 2015 / Accepted: 1 October 2015 / Published: 15 October 2015

\begin{abstract}
As a new branch of MOFs which are composed of biocompatible metal ions and organic ligands, bio-metal-organic frameworks (bio-MOFs) have attracted much attention recently. Bio-MOFs feature multiple Lewis basic sites which have strong interaction with $\mathrm{CO}_{2}$ molecules, thus they have great potential in the separation and purification of gas mixtures containing $\mathrm{CO}_{2}$. In this work, molecular simulation studies were carried out to investigate the adsorption and diffusion behaviors of $\mathrm{CO}_{2} / \mathrm{N}_{2}$ gas mixtures in bio-MOF-11. Results show that bio-MOF-11 displays excellent adsorption selectivity towards $\mathrm{CO}_{2}$ in $\mathrm{CO}_{2} / \mathrm{N}_{2}$ gas mixtures which was dominated by electrostatic interaction between material and $\mathrm{CO}_{2}$. In addition, we found both $\mathrm{CO}_{2}$ and $\mathrm{N}_{2}$ molecules were preferably adsorbed around the pyrimidine ring and exocyclic amino and transferred to the secondary favorable adsorption sites (methyl groups) with increasing pressure. Bio-MOF-11 membranes show superior permeation selectivity, but low permeability for $\mathrm{CO}_{2} / \mathrm{N}_{2}$ gas systems. The reason is that the small pores restrict the movement of gas molecules, leading to the observed low permeability. The information obtained in this work can be applied to other theoretical and experimental studies of bio-MOFs adsorbents and membranes in the future.
\end{abstract}

Keywords: separation; diffusion; flue gas; bio-metal-organic frameworks (Bio-MOFs); molecular simulation 


\section{Introduction}

Reduction of greenhouse gas emissions is an important challenge faced by all countries in the world. A major source of carbon emissions is plant flue gas, which mainly consists of $\mathrm{CO}_{2}$ and $\mathrm{N}_{2}$. In the past decades, a number of methods have been proposed to solve the problem including cryogenic distillation, amine scrubbing, and sorbent adsorption [1]. Among these methods, pressure swing adsorption (PSA) technology and membrane separation based on porous materials are known to be efficient and affordable processes for $\mathrm{CO}_{2}$ removal from flue streams.

To capture $\mathrm{CO}_{2}$ and separate the gas mixture efficiently, it is important to choose the appropriate materials. Metal-organic frameworks (MOFs) have emerged as a kind of novel porous materials are thought to be promising materials for gas storage and separation [2-6]. They are formed by coordinating transition or lanthanide metal cations with organic linkers. Compared to traditional materials, they have advantages of low density, high specific area, and more tunable structures. Besides, they are synthesized under milder conditions, thus, MOFs have drawn much attention in recent years [7-11] and many researches [12-22] have been carried out to study the performance of MOFs. For example, we have studied the adsorption separation of $\mathrm{CO}_{2} / \mathrm{N}_{2}, \mathrm{CO}_{2} / \mathrm{CH}_{4}$, and $\mathrm{CH}_{4} / \mathrm{N}_{2}$ by ZIFs [5]. Zhao et al. [13] studied the permeation and gas mixture separation properties of MOF-5 membranes. Babarao and Jiang [23] investigated the energetics and dynamics of ibuprofen in MOFs. Zhang et al. [24] investigated the adsorption of $\mathrm{C}_{1}-\mathrm{C}_{4}$ alcohols in ZIF-8. Their simulation results reveal that MOFs are outstanding materials and can be widely used in gas purification, membrane separation, catalysis, and drug delivery.

Bio-metal organic frameworks (bio-MOFs) are a new branch of MOFs which are composed of biocompatible metal ions and organic ligands. For example, some bio-MOFs are synthesized by using adenine and short peptide biological molecules as the ligands, and $\mathrm{Zn}$ and $\mathrm{Co}$ ions as the metal ions $[25,26]$. Recently, some experiments and simulations have been carried out to investigate the properties of bio-MOFs. An et al. [26] found that bio-MOF-11 has extraordinary ability of $\mathrm{CO}_{2}$ capture than many other MOFs. Erhan et al. [27] predicted permeation selectivities and gas permeabilities of bio-MOF membranes for three kinds of different gas mixtures, compared these bio-MOFs with several other nanoporous membranes, and found that bio-MOF-11 was a good candidate for membrane separation.

In this work, molecular simulations were carried out to calculate the adsorption of $\mathrm{CO}_{2} / \mathrm{N}_{2}$ mixture in bio-MOF-11 and discussed the relationship between temperature, pressure, electrostatic force, and the adsorption selectivity. Then we focus our studies on gas diffusion, permeability, and permeation selectivity in bio-MOF-11 membranes and compared these properties with some common MOFs and zeolites. The results can be applied to evaluate the performance of gas adsorption and membrane separation in bio-MOF.

\section{Results and Discussion}

\subsection{Pure Gases}

In order to verify the reasonableness of Lennard-Jones (LJ) force field parameters and charges of bio-MOF-11 and the gas molecules, we compared the calculated adsorption isotherms of pure $\mathrm{CO}_{2}$ and $\mathrm{N}_{2}$ with experimental values [26], as shown in Figure 1. 


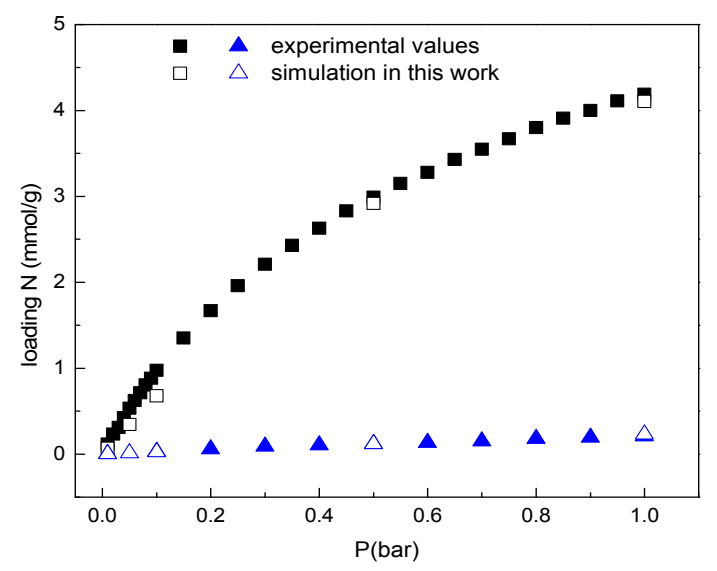

Figure 1. Adsorption isotherms of single $\mathrm{CO}_{2}$ (squares) and $\mathrm{N}_{2}$ (triangles) in bio-MOF-11 at $298 \mathrm{~K}$ (filled symbols represent experiment values from literature and open symbols represent the results from the current simulation work).

From Figure 1, we can see that the simulation results of a single component gas agree well with the experimental data published in the literature. The good agreement implies the accuracy of the models, LJ potential parameters, and charges used in our simulations. Therefore, we believe the following calculations of adsorption selectivity, diffusion selectivity, and permeability are reliable.

\subsection{The Adsorption Selectivity of $\mathrm{CO}_{2} / \mathrm{N}_{2}$ Gas Mixture}

To evaluate the separation performance of bio-MOF-11, we firstly predicted the adsorption selectivity of $\mathrm{CO}_{2}$ by ideal adsorbed solution theory (IAST) and compared the prediction with the Grand-canonical Monte Carlo (GCMC) simulation results for equimolar and 15:85 binary mixtures of $\mathrm{CO}_{2} / \mathrm{N}_{2}$, as shown in Figure 2. From Figure 2, we can see that the tendency of predicted selectivity by IAST is basically accordance with the simulation results but the value of selectivity is underestimated. We found $\mathrm{CO}_{2}$ concentration has a great impact on the selectivity and a small difference in the mole fractions may results in great selectivity discrepancies.

Then we made a comparison between our simulation results and eight other MOFs, as shown in Figure 3. The data of other MOFs are taken from our previous works [28] and other literatures [5,29,30]. Figure 3 shows that bio-MOF-11 displays better separation performance than other eight common MOFs, which indicates that bio-MOF-11 can easily separate $\mathrm{CO}_{2} / \mathrm{N}_{2}$ gas mixtures. This can be attributed to the fact that the adenine structural units in bio-MOF-11 can provide multiple Lewis base sites which have strong adsorption capacity for $\mathrm{CO}_{2}$ gas molecules, resulting in good selective adsorption performance for $\mathrm{CO}_{2}$ from $\mathrm{CO}_{2} / \mathrm{N}_{2}$ gas mixtures. In addition, from Figure 3 we can see that the adsorption selectivity in bio-MOF-11 increases with the increase of pressure in the low pressure region, then remains stable with further increasing pressure. 


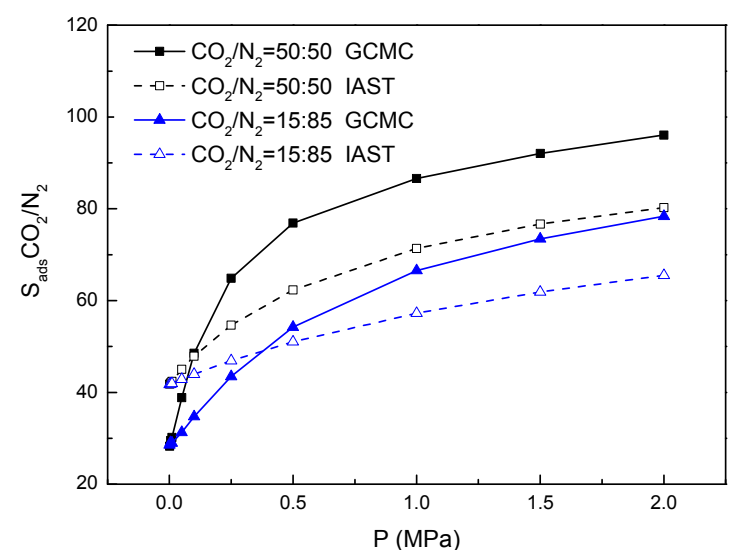

Figure 2. Adsorption selectivity of $\mathrm{CO}_{2} / \mathrm{N}_{2}$ mixture (50:50 and 15:85) in bio-MOF-11 as a function of total pressure at $298 \mathrm{~K}$. The filled symbols are from simulation and the open symbols are from IAST.
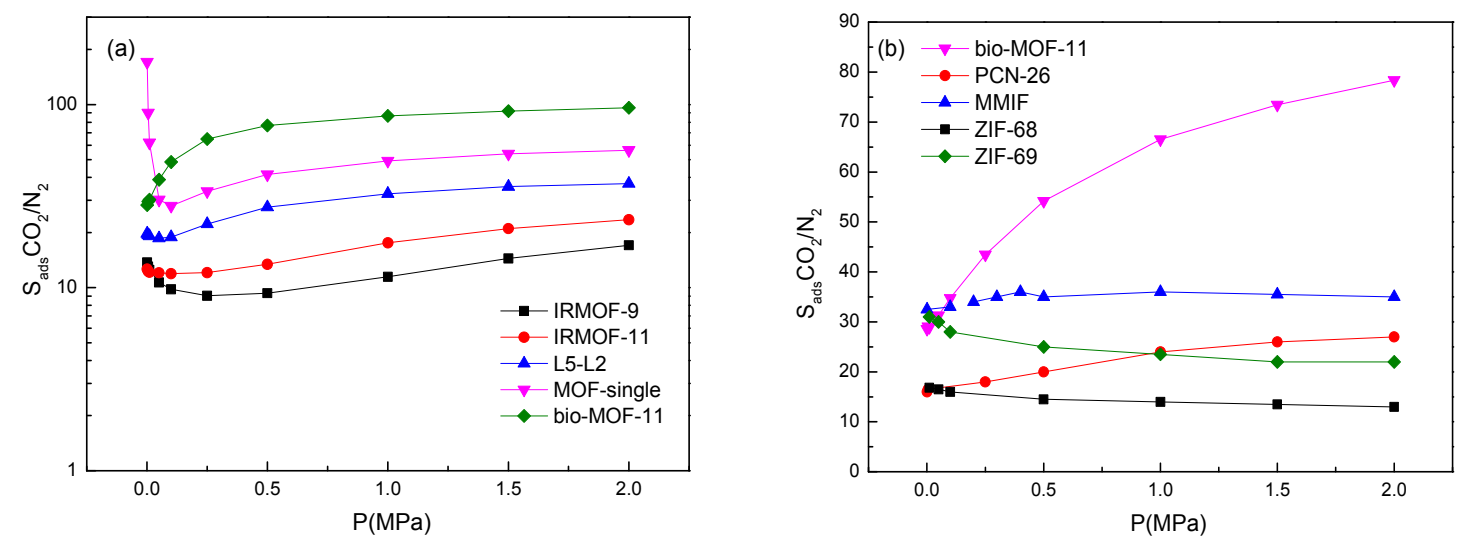

Figure 3. Comparison of adsorption selectivities for (a) equimolar and (b) 15:85 binary gas mixtures of $\mathrm{CO}_{2} / \mathrm{N}_{2}$ as a function of total bulk pressure in bio-MOF-11 with other eight MOFs at $298 \mathrm{~K}$.

To investigate the adsorption mechanism of gas mixtures and find the most favorable adsorption site(s) in bio-MOF-11, we calculated the radial distribution functions of $\mathrm{CO}_{2}$ and $\mathrm{N}_{2}$ from equimolar and 15:85 binary mixtures of $\mathrm{CO}_{2} / \mathrm{N}_{2}$ around some heavy atoms in bio-MOF-11, as shown in Figure 4.

Three remarkable peaks can be clearly seen from Figure $4 a, c$ in the vicinity of $r=4 \AA$, which means $\mathrm{CO}_{2}$ molecules prefer to be adsorbed around N1, N3, and C4 first, as shown in Figure 5. We can also see two slightly pronounced peaks around $\mathrm{C} 3$ and $\mathrm{C} 7$, which are the less favorable locations. Among them, N1, C4, and C3 are located at pyrimidine ring and N3 represents the exocyclic amino nitrogen atom. This suggests that there are strong adsorption interactions between pyrimidine and $\mathrm{CO}_{2}$ molecules. Similarly, the small peak around $\mathrm{C} 7$ indicates the methyl $\left(-\mathrm{CH}_{3}\right)$ group is also favorable for $\mathrm{CO}_{2}$ adsorption. A similar tendency of $\mathrm{N}_{2}$ could also be seen from Figure $4 \mathrm{~b}$,d. In a word, the preferential adsorption sites of $\mathrm{CO}_{2}$ and $\mathrm{N}_{2}$ in bio-MOF-11 are the adenine linkers rather than metal ions. This suggests that we can modify the ligands by adding a certain amount of pyrimidine to enhance the material adsorption separation performance. 

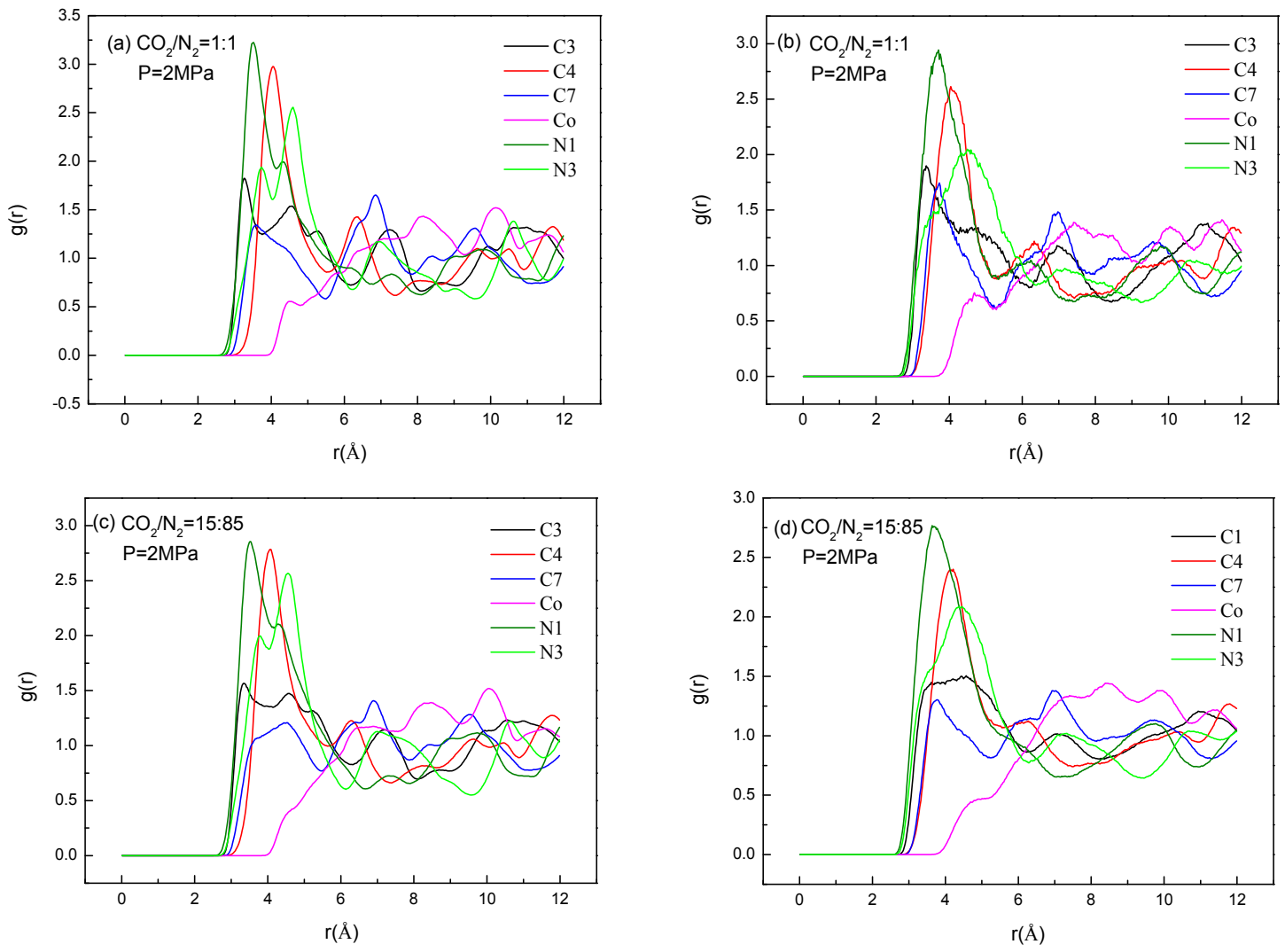

Figure 4. Radial distribution functions of (a) $\mathrm{CO}_{2}$ and (b) $\mathrm{N}_{2}$ from equimolar binary mixtures of $\mathrm{CO}_{2} / \mathrm{N}_{2}$; and radial distribution functions of (c) $\mathrm{CO}_{2}$ and (d) $\mathrm{N}_{2}$ from 15:85 binary mixtures of $\mathrm{CO}_{2} / \mathrm{N}_{2}$ around framework atoms at $2 \mathrm{MPa}$.

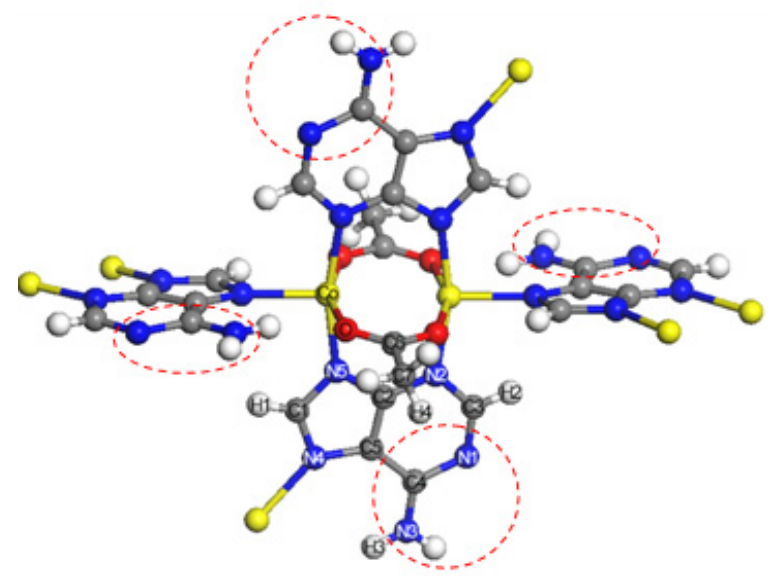

Figure 5. The most favorable adsorption sites of bio-MOF-11 cluster. (Co, yellow; C, grey; $\mathrm{H}$, white; $\mathrm{O}$, red; and N, blue).

Figure 6 shows the simulation snapshots of $\mathrm{CO}_{2}$ from equimolar binary mixtures of $\mathrm{CO}_{2} / \mathrm{N}_{2}$ in bio-MOF-11 at three different pressures and $298 \mathrm{~K}$. Due to the small amount of $\mathrm{N}_{2}$ adsorption in the material, we removed the $\mathrm{N}_{2}$ molecules in Figure 6. From the pictures we can see that under low pressure, $\mathrm{CO}_{2}$ molecules with strong electrostatic forces and large quadrupole moment firstly occupy the best adsorption sites, i.e., the Lewis basic pyrimidine and amino groups. As the pressure and the $\mathrm{CO}_{2}$ adsorption quantity increase gradually, the best adsorption locations are all occupied, resulting in 
the transfer of $\mathrm{CO}_{2}$ molecules to the secondary favorable adsorption sites (methyl groups). Finally, when the pressure reaches a certain value, the $\mathrm{CO}_{2}$ molecules fill all the cavities that become saturated.

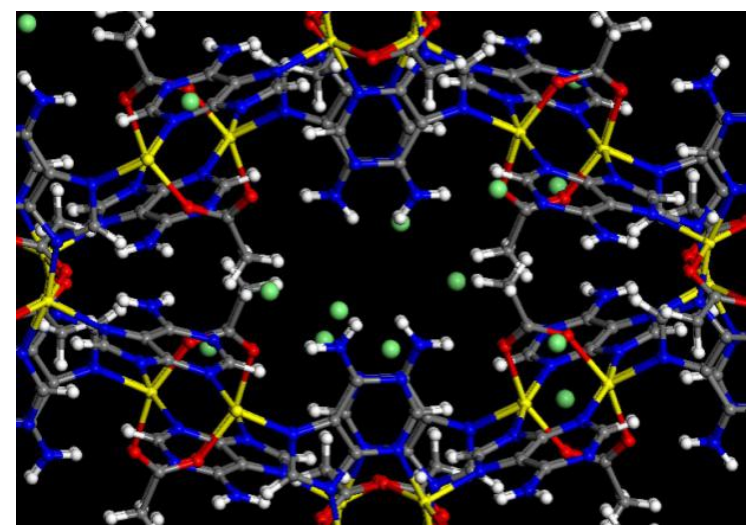

(a)

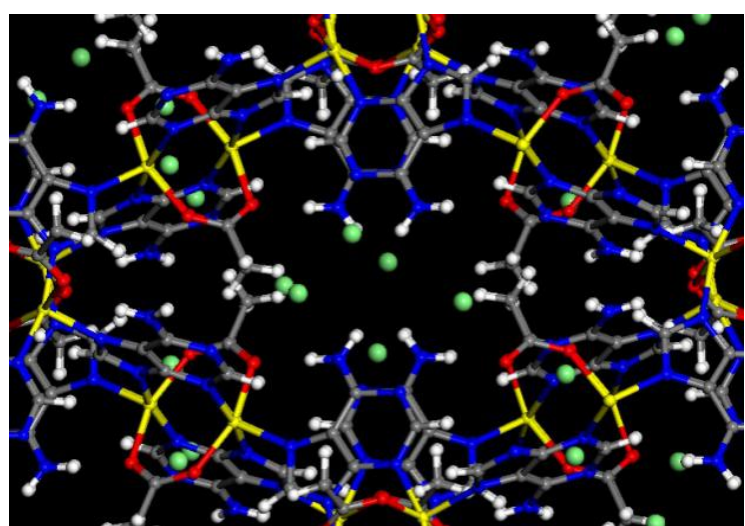

(b)

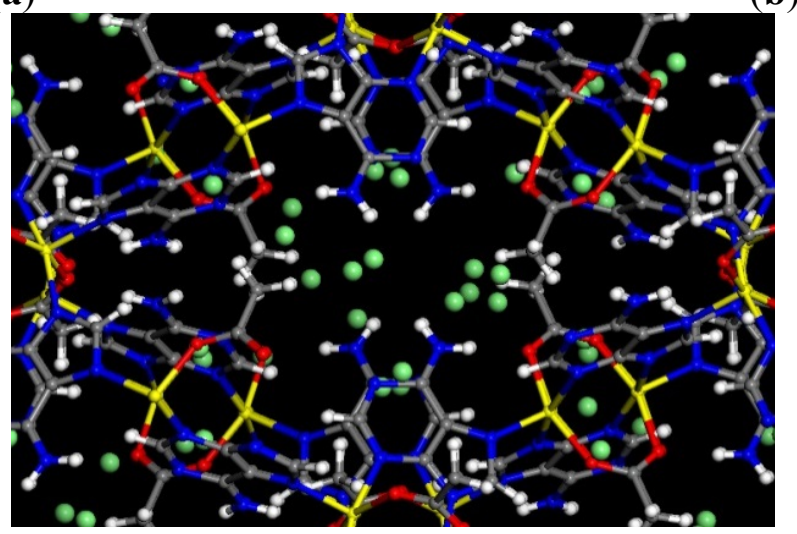

(c)

Figure 6. Simulation snapshots of $\mathrm{CO}_{2}$ from equimolar binary mixtures of $\mathrm{CO}_{2} / \mathrm{N}_{2}$ in bio-MOF-11 at (a) $0.05 \mathrm{MPa}$; (b) $0.1 \mathrm{MPa}$; and (c) $1 \mathrm{MPa}$ and $298 \mathrm{~K}$. $\mathrm{CO}_{2}$ molecules are represented by green balls. The frameworks of bio-MOF-11 are represented by ball-and-stick model. (Co, yellow; C, grey; $\mathrm{H}$, white; $\mathrm{O}$, red; and N, blue).

Because of the weaker interaction between the material and $\mathrm{N}_{2}$ molecules compared with $\mathrm{CO}_{2}$, the adsorption capacity of $\mathrm{N}_{2}$ is very small. At low pressure, $\mathrm{N}_{2}$ molecules are also adsorbed at $\mathrm{N} 1$ and $\mathrm{N} 3$. As the amount of $\mathrm{CO}_{2}$ in the material increases, the strong material- $\mathrm{CO}_{2}$ and $\mathrm{CO}_{2}-\mathrm{CO}_{2}$ intermolecular interactions compel $\mathrm{N}_{2}$ away from the optimal position and transfer to the secondary favorable adsorption sites even in cavities.

\subsection{Effect of Electrostatic Interactions on Adsorption Selectivity in Bio-MOF-11}

In this part, we consider three cases to investigate the influence of electrostatic force. In case 1, all the electrostatic interactions were considered. In case 2, we turned off all the Coulombic interactions including adsorbates-adsorbates and adsorbates-adsorbents. In case 3, we only considered the electrostatic forces between gas molecules. Equimolar binary mixtures of $\mathrm{CO}_{2} / \mathrm{N}_{2}$ and 15:85 binary mixtures of $\mathrm{CO}_{2} / \mathrm{N}_{2}$ were studied and the simulation results are shown in Figure 7. 

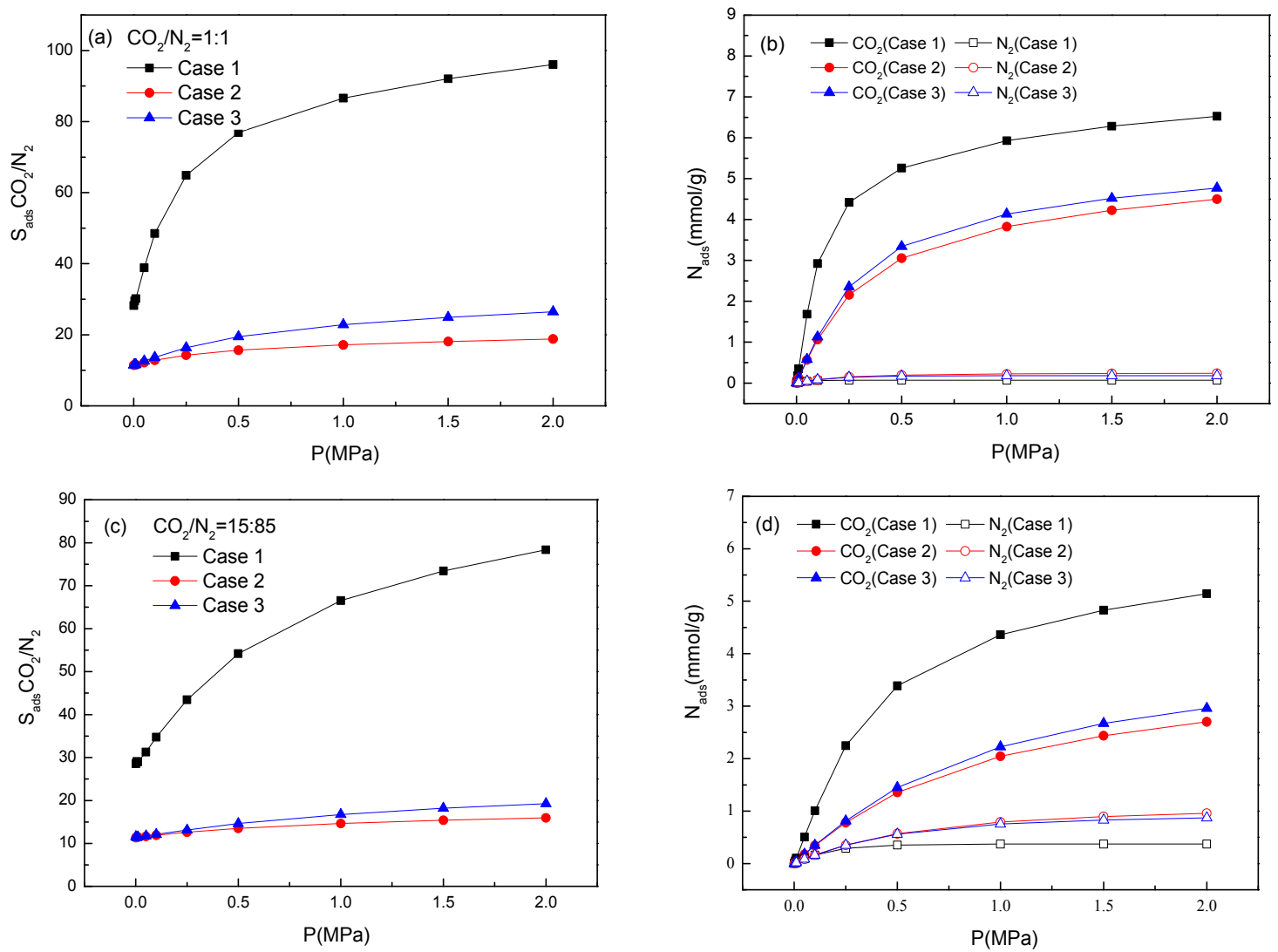

Figure 7. Effect of electrostatic interactions on the (a) adsorption selectivities for $\mathrm{CO}_{2}$ and (b) adsorption isotherms of $\mathrm{CO}_{2}$ and $\mathrm{N}_{2}$ from equimolar binary mixtures of $\mathrm{CO}_{2} / \mathrm{N}_{2}$; and effect of electrostatic interactions on the (c) adsorption selectivities for $\mathrm{CO}_{2}$ and (d) adsorption isotherms of $\mathrm{CO}_{2}$ and $\mathrm{N}_{2}$ from 15:85 binary mixtures of $\mathrm{CO}_{2} / \mathrm{N}_{2}$ in bio-MOF-11 at $298 \mathrm{~K}$.

Figure $7 \mathrm{a}, \mathrm{c}$ show that the adsorption selectivity of $\mathrm{CO}_{2} / \mathrm{N}_{2}$ gas mixture decreased sharply when all the Coulombic interactions were turned off. This phenomenon indicates that electrostatic interactions play an important role in $\mathrm{CO}_{2} / \mathrm{N}_{2}$ adsorption separation. Comparing with electrostatic interactions between adsorbates, the Coulombic forces of material-gas have greater impact on the adsorption selectivity. It can be clearly seen from Figure $7 \mathrm{~b}$,d that the electrostatic field of bio-MOF-11 greatly improves the adsorption quantity of $\mathrm{CO}_{2}$, but less enhances the $\mathrm{N}_{2}$ adsorption. Therefore, the existence of framework charges results in a much higher selectivity for both $\mathrm{CO}_{2} / \mathrm{N}_{2}$ systems.

\subsection{Effect of Temperature on Adsorption Selectivity in Bio-MOF-11}

To investigate the impact of temperature on the adsorption selectivity in bio-MOF-11, equimolar and 15:85 binary mixed systems of $\mathrm{CO}_{2} / \mathrm{N}_{2}$ were chosen for simulation, as shown in Figure 8 below. 

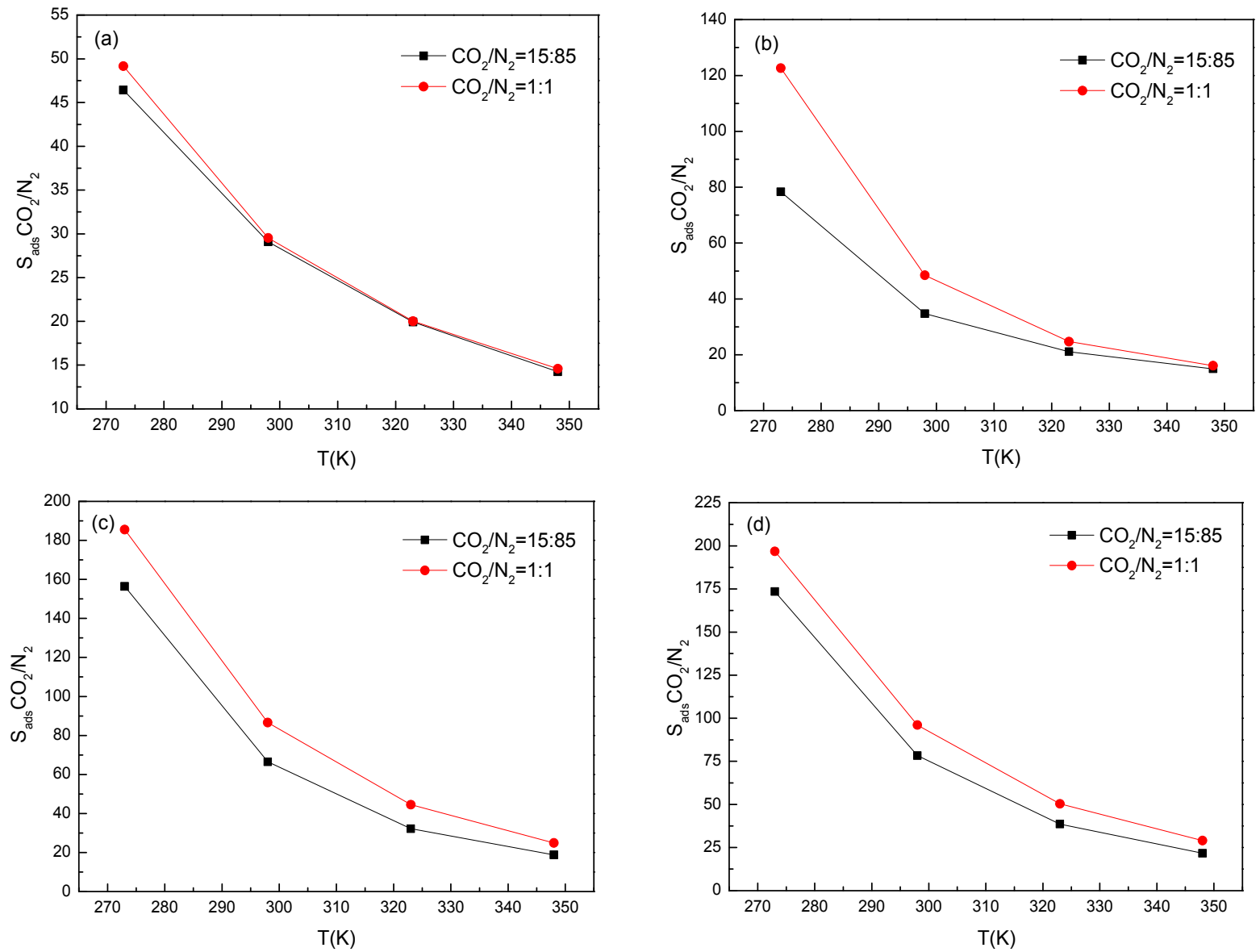

Figure 8. The adsorption selectivity for equimolar and 15:85 binary mixtures of $\mathrm{CO}_{2} / \mathrm{N}_{2}$ at (a) $0.005 \mathrm{MPa}$; (b) $0.1 \mathrm{MPa}$; (c) $1 \mathrm{MPa}$; and (d) $2 \mathrm{MPa}$ as a function of temperature.

From Figure 8 we can see that the adsorption selectivity of $\mathrm{CO}_{2}$ decreases with increasing temperature. At low temperature, the adsorption selectivity decreases sharply. With the temperature increases, it starts to slow down the drop. In addition we found that the higher the pressure, the greater the influence of temperature on the selectivity was.

\subsection{Gas Diffusion and Permeation Selectivity of Bio-MOF-11 Membranes}

Figure 9 displays the diffusion selectivities for equimolar and 15:85 binary gas mixtures of $\mathrm{CO}_{2} / \mathrm{N}_{2}$ as a function of total bulk pressure in bio-MOF-11. It can be seen that $\mathrm{S}_{\text {diff }}<1$, which means the diffusion velocity of $\mathrm{N}_{2}$ is faster than that of $\mathrm{CO}_{2}$. It is known that adsorbability of materials, weight, and size of gas molecules are the main factors influencing gas diffusion. The diameters of $\mathrm{CO}_{2}$ and $\mathrm{N}_{2}$ molecules are very close, resulting in the similar restriction for the movement of $\mathrm{CO}_{2}$ and $\mathrm{N}_{2}$ in cavities. However the weaker interactions between bio-MOF-11 and $\mathrm{N}_{2}$ lead to faster diffusion of $\mathrm{N}_{2}$ than $\mathrm{CO}_{2}$. Therefore, the interactions between material and gas molecules instead of the size of guest molecules give rise to the difference of the diffusion velocity for $\mathrm{CO}_{2} / \mathrm{N}_{2}$ gas mixture. 


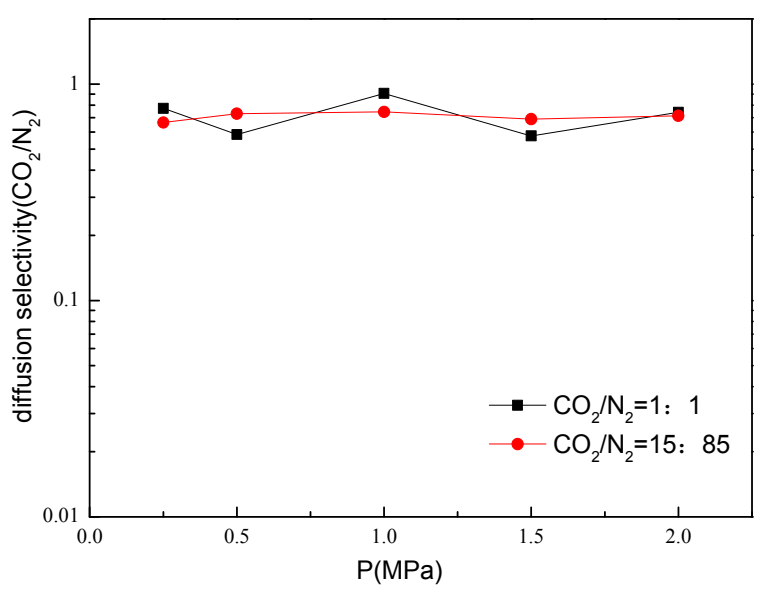

Figure 9. The diffusion selectivities for equimolar and 15:85 binary gas mixtures of $\mathrm{CO}_{2} / \mathrm{N}_{2}$ as a function of total bulk pressure in bio-MOF-11.

Permeation selectivity is usually used to quantitatively study the gas separation performance of membranes and can be estimated as the product of adsorption and diffusion selectivity for a binary mixture [14,31,32], $S_{\text {permi }} / j=S_{a d s} i / j \times S_{\text {diffi }} / j$. The results of $\mathrm{CO}_{2} / \mathrm{N}_{2}$ gas mixtures in bio-MOF-11 are given in Figure 10 and the information of other materials are taken from [33-35]. It is clearly noted that bio-MOF-11 exhibits higher membrane selectivity than most of the materials studied because of the high adsorption selectivity. A similar phenomenon also occurs in bio-MOF-11 membrane separation of $\mathrm{CH}_{4} / \mathrm{H}_{2}, \mathrm{CO}_{2} / \mathrm{CH}_{4}$, and $\mathrm{CO}_{2} / \mathrm{H}_{2}$ gas mixtures [27].
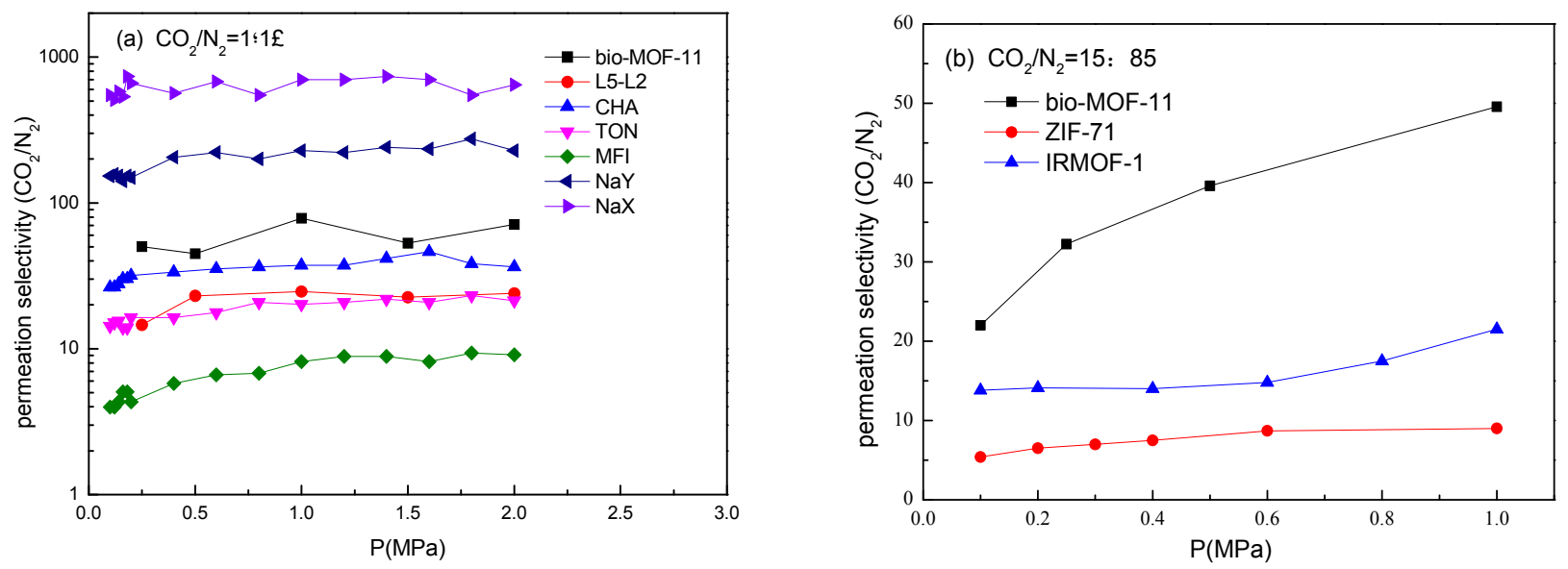

Figure 10. Comparison of permeation selectivities for (a) equimolar and (b) 15:85 binary gas mixtures of $\mathrm{CO}_{2} / \mathrm{N}_{2}$ as a function of total bulk pressure in bio-MOF-11 with other MOFs and zeolites at $298 \mathrm{~K}$.

\subsection{Gas Permeabilities and Selectivities of Bio-MOF-11 Membranes for $\mathrm{CO}_{2} / \mathrm{N}_{2}$ Mixtures.}

When studying the separation performance of membrane materials, it is important to investigate the permeation selectivity as well as permeability of membranes to judge if the material is a good candidate for gas membrane separation. Ideal membranes with characteristics of high osmotic selectivity and good permeability can not only greatly improve the purity of gas after purification but also complete the gas separation task within the allotted time. Therefore, there is a compromise between the 
permeation selectivity and permeability which must be considered in membrane selection. The membrane permeabilities were estimated by the following equation proposed by Krishna and van Baten [33]:

$$
\prod_{i}=\varphi \cdot D_{s, i} \cdot c_{i} / f_{i}
$$

where $\varphi$ is the porosity of the material; $D_{s, i}$ is the self-diffusivity of gas $i$ in the material $\left(\mathrm{m}^{2} / \mathrm{s}\right) ; c_{i}$ is the molar concentration of adsorbate $i$ in menbrane $\left(\mathrm{mol} / \mathrm{m}^{3}\right) ; f_{i}$ is the bulk phase fugacity of species $i(\mathrm{~Pa})$; and $\Pi_{i}$ is the permeability of species $i(\mathrm{~mol} / \mathrm{m} / \mathrm{s} / \mathrm{Pa})$. Then the calculated results should be converted into the value in Barrer $\left(1\right.$ Barrer $\left.=3.348 \times 10^{-16} \mathrm{~mol} / \mathrm{m} / \mathrm{s} / \mathrm{Pa}\right)$.

Figure 11 shows the relationship between permeation selectivity and gas permeability of bio-MOF-11 together with other common porous materials at $1 \mathrm{MPa}$. The data for other membranes are taken from [28,31,33]. Bio-MOF-11 shows superior permeation selectivity for $\mathrm{CO}_{2} / \mathrm{N}_{2}$ mixed gas systems but low permeability. That is the strong electrostatic interactions between $\mathrm{CO}_{2}$ and bio-MOF-11 lead to the high adsorption selectivity and permeation selectivity. However, the small cavities of bio-MOF-11 restrict the movement of gas molecules and hinder the diffusion of guest molecules, resulting in the low permeability. It is clearly seen that $\mathrm{NaX}$ and $\mathrm{NaY}$ are good membranes for separation because of the compromise between permeation selectivity and permeability. The strong interactions between $\mathrm{Na}^{+}$ and $\mathrm{CO}_{2}$ cause high permeation selectivity, and the open, big pores lead to great permeability. Therefore we think that the structure of bio-MOF-11 could be adjusted to enlarge the pore size and then the permeability will be greatly improved.
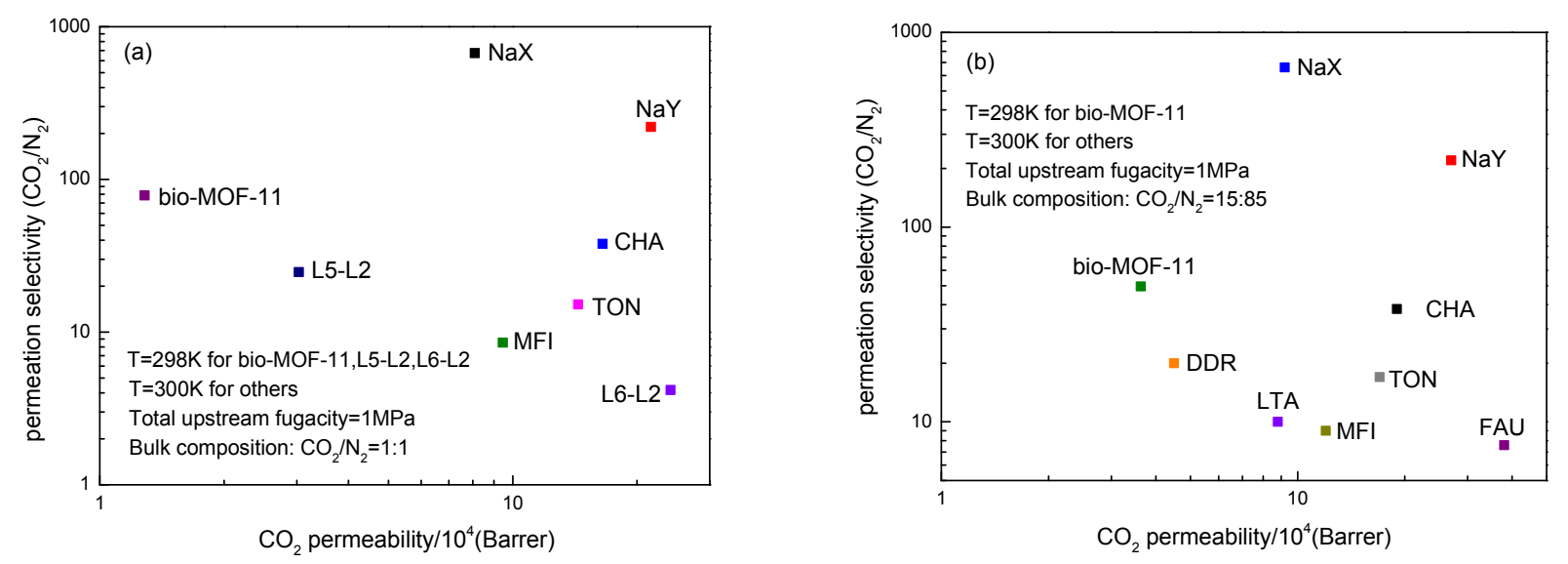

Figure 11. Comparison of permeation selectivity and permeability of MOFs membranes and zeolites for (a) 1:1 and (b) 15:85 $\mathrm{CO}_{2} / \mathrm{N}_{2}$ gas mixtures.

\section{Simulation Section}

\subsection{Bio-MOF-11 Structure}

The Bio-MOF-11 structure was constructed from experimental single-crystal X-ray diffraction data [26] by Material Studio software. The topology of the material is tetragonal and the space group is I41/A. Bio-MOF-11 consists of cobalt-adeninate-acetate paddle wheel clusters and adenine, which has multiple Lewis basic sites including an amino group and pyrimidine nitrogens [27]. The detailed structural properties of bio-MOF-11 are summarized in Table 1. Figure 12 illustrates the structure of bio-MOF-11 from the three dimensional directions. 
Table 1. Structural properties of bio-MOF-11 studied in this work.

\begin{tabular}{ccccccc}
\hline Material & Topology $^{a}$ & Unit cell $^{\mathbf{a}}(\AA)$ & Cell Angle $^{\mathbf{a}}(\mathbf{D e g})$ & $\boldsymbol{\rho}_{\text {crys }}{ }^{\mathbf{b}}\left(\mathbf{g} / \mathbf{c m}^{3}\right)$ & $\mathbf{V}_{\text {free }}{ }^{\mathbf{b}}\left(\mathbf{c m}^{3} / \mathbf{g}\right)$ & Porosity $^{\mathbf{b}}$ \\
\hline \multirow{2}{*}{ bio-MOF-11 } & tetragonal & $\begin{array}{c}\mathrm{a}=\mathrm{b}=15.43 \\
\mathrm{c}=22.775\end{array}$ & $\alpha=\beta=\gamma=90$ & 1.234 & 0.318 & 0.393 \\
\hline
\end{tabular}

a is obtained from XRD experiment in the literatures [26] and ${ }^{\mathrm{b}}$ is obtained from our simulations.
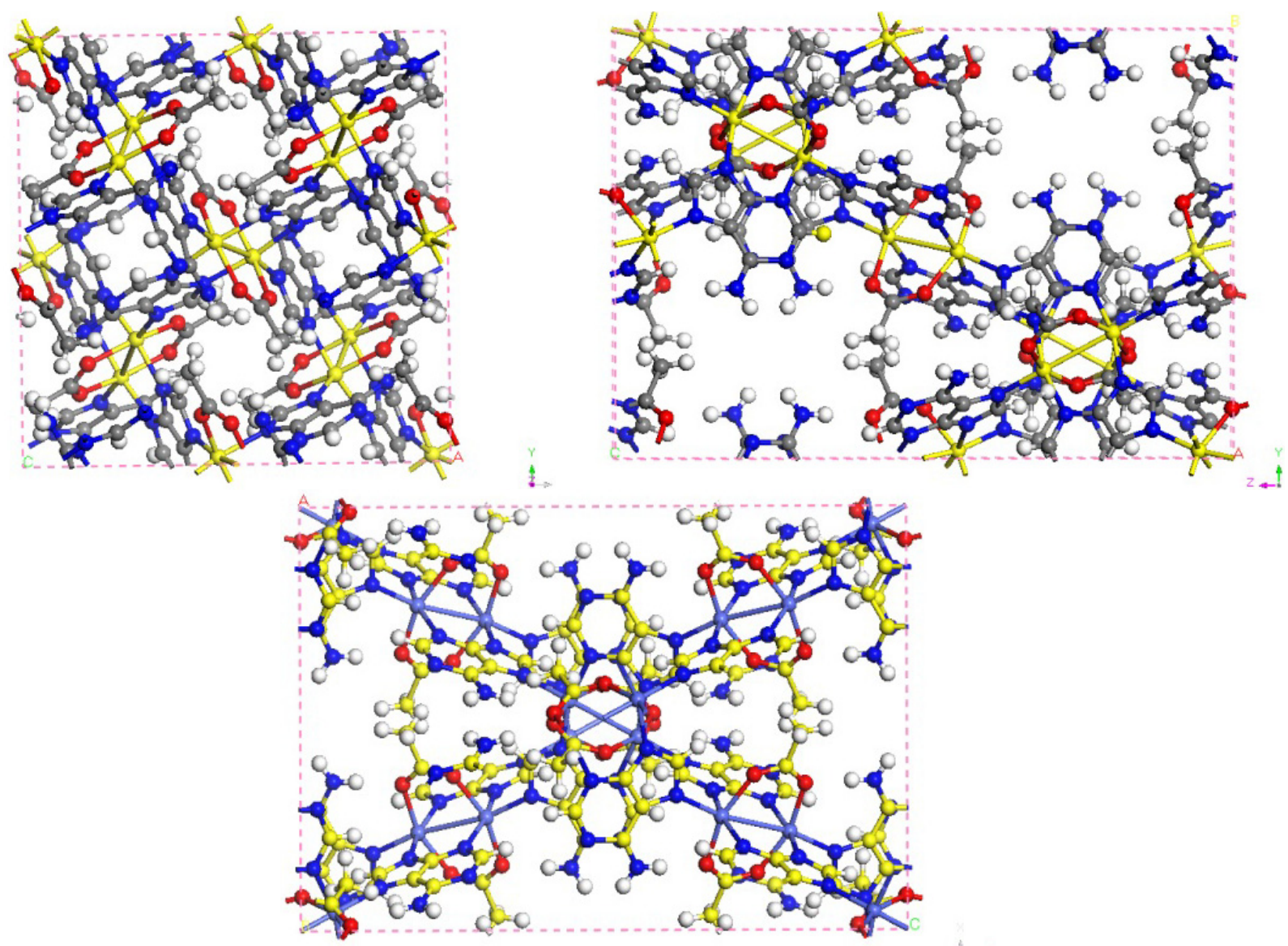

Figure 12. Unit cell crystal structure of bio-MOF-11 used in the simulations (Co, yellow; $\mathrm{C}$, grey; $\mathrm{H}$, white; $\mathrm{O}$, red; and $\mathrm{N}$, blue).

\subsection{Force Field}

It is well-known that the selection of force field plays an important role on calculation results. In this work, $\mathrm{CO}_{2}$ were treated as rigid linear molecular model with three atoms which was usually used in the simulation of gas adsorption. The bond length of C-O is $0.116 \mathrm{~nm}$ and the partial point charges which centered at each LJ site are $\mathrm{q}_{\mathrm{C}}=+0.7$ e and $\mathrm{q}_{\mathrm{O}}=-0.35$ e. $\mathrm{N}_{2}$ molecule was represented as a three-site model with two sites located at two $\mathrm{N}$ atoms and the third one located at its center of mass (COM) [36]. The charges of $\mathrm{N}$ atoms and COM are -0.482 e and +0.964 e respectively. N-N bond length is $0.11 \mathrm{~nm}$. The $\mathrm{LJ}$ force field parameters for $\mathrm{CO}_{2}$ and $\mathrm{N}_{2}$ are taken from TraPPE [36] and listed in Table 2 together with bio-MOF-11. The site-site LJ potentials as well as Coulombic potentials were applied to calculate the guest molecular interactions. 
Table 2. LJ potential parameters for $\mathrm{CO}_{2}, \mathrm{~N}_{2}$, and bio-MOF-11 studied in this work.

\begin{tabular}{ccc}
\hline Atom & $\boldsymbol{\sigma}(\boldsymbol{\AA})$ & $\boldsymbol{\varepsilon} / \mathbf{k}_{\mathbf{B}}(\mathbf{K})$ \\
\hline $\mathrm{CO}_{2} \mathrm{C}$ & 2.80 & 27.0 \\
$\mathrm{CO}_{2} \mathrm{O}$ & 3.05 & 79.0 \\
$\mathrm{~N}_{2} \mathrm{~N}$ & 3.31 & 36.0 \\
$\mathrm{MOF}$ Co & 2.56 & 7.05 \\
MOF_C & 3.43 & 52.84 \\
MOF_H & 2.57 & 22.14 \\
MOF_O & 3.12 & 30.19 \\
MOF_N & 3.26 & 34.72 \\
\hline
\end{tabular}

The LJ potential parameters for bio-MOF-11 are taken from universal force field (UFF) [37]. At the same time, we also combine LJ potential and Coulombic force to describe the interactions between adsorbents and adsorbates. The atomic partial charges of bio-MOF-11 we used are listed in Table 3. All electrostatic interactions were handled using the Ewald summation technique [38] and all of the LJ cross interaction parameters were obtained by Lorentz-Berthelot mixing rules.

Table 3. Atomic partial charges for bio-MOF-11.

\begin{tabular}{cccccccccc}
\hline Atom & Co & O & C1 & C2 & C3 & C4 & C5 & C6 & C7 \\
\hline Charge & 0.68 & -0.798 & 0.101 & 0.531 & 0.526 & 0.711 & 0.292 & 0.903 & -0.489 \\
Atom & $\mathrm{N} 1$ & $\mathrm{~N} 2$ & $\mathrm{~N} 3$ & $\mathrm{~N} 4$ & $\mathrm{~N} 5$ & $\mathrm{H} 1$ & $\mathrm{H} 2$ & $\mathrm{H} 3$ & $\mathrm{H} 4$ \\
Charge & -0.761 & -0.651 & -1.013 & -0.099 & -0.417 & 0.066 & 0.008 & 0.415 & 0.126 \\
\hline
\end{tabular}

\subsection{Simulation Details}

In this work, GCMC simulations were employed to calculate the adsorption isotherms of the gas mixture in bio-MOF-11. The material in the simulation was modeled as rigid structure, which ignored the skeleton stretching and bending vibration. The numbers of the unit cells in the simulation box were $2 \times 2 \times 2$ and periodic boundary conditions were applied in three dimensional directions. The LJ potential cutoff radius $r_{c}$ is $1.28 \mathrm{~nm}\left(r \geq r_{c}, U_{L J}=0\right)$. In GCMC simulations, chemical potential which was computed by Peng-Robinson equation of state served as input quantity to calculate the gas adsorption. The total GCMC simulation consisted of $1.7 \times 10^{6}$ steps. The first $1 \times 10^{5}$ steps are for structural relaxation, the next $1 \times 10^{5}$ steps are for equilibration, and the last $1.5 \times 10^{6}$ steps are for statistical thermodynamics calculation.

Equilibrium Molecular Dynamics (EMD) simulations in the NVT ensemble were carried out to obtain the gas diffusivity and permeability of bio-MOF-11 membranes. The Nose-Hoover thermostat [39] was chosen to keep the temperature of simulation constant and the time steps of simulation were set 1.0 fs. For each state, the total MD simulation consisted of $5 \times 10^{6}$ steps. $1 \times 10^{5}$ steps were used to relax the framework and the subsequent $2 \times 10^{5}$ steps for equilibration. Mean-Square Displacements (MSD) were outputted every 1000 steps and followed with calculating the self-diffusion coefficient by Einstein relation:

$$
D_{S}^{x}=\frac{1}{2} \lim _{t \rightarrow \infty} \frac{d}{d t}\left\langle[x(t)-x(0)]^{2}\right\rangle
$$


where $x(t)$ is the position vector of tracer particle along the $\mathrm{x}$ axis at time $\mathrm{t}$ and angle brackets represent the ensemble average. Similarly, we can obtain the self-diffusion coefficients on the directions of y and $\mathrm{z}$ axis. Therefore, the mean self-diffusion coefficient which is often used to evaluate the performance of gas diffusion would be calculated by the following equation:

$$
D=\frac{D_{x}+D_{y}+D_{z}}{3}
$$

\section{Conclusions}

We used GCMC and EMD simulation techniques to study the adsorption and diffusion properties of $\mathrm{CO}_{2} / \mathrm{N}_{2}$ gas mixture in bio-MOF-11. We found Bio-MOF-11 is suitable for adsorption separation of $\mathrm{CO}_{2} / \mathrm{N}_{2}$ gas mixtures and capturing $\mathrm{CO}_{2}$ molecules because of the strong interaction between the Lewis base sites located on the adenine linkers and $\mathrm{CO}_{2}$ molecules. The electrostatic material-gas interaction plays an important role in $\mathrm{CO}_{2} / \mathrm{N}_{2}$ adsorption separation. By investigating the gas diffusion separation in bio-MOF-11, we found the diffusion velocity of $\mathrm{N}_{2}$ is faster than that of $\mathrm{CO}_{2}$. Bio-MOF-11 shows excellent permeation selectivity for $\mathrm{CO}_{2} / \mathrm{N}_{2}$ mixed gas systems, but low permeability due to the small cavities of the structure. Therefore in order to improve the permeability of bio-MOF-11 membranes some adjustments have to be made to enlarge the cavities.

\section{Acknowledgments}

This work was supported by the open funding project from State Key Laboratory of Offshore Oil Exploitation of China, the National Natural Science Foundation of China (No. 21276272), and Beijing Youth Talent Plan (YETP0674).

\section{Author Contributions}

Zhi Li and Gangqiang Xu performed molecular simulations. Bei Liu, Xin Lv, Guangjin Chen, Changyu Sun, Peng Xiao, and Yifei Sun performed data analysis. Zhi Li prepared figures and tables. Zhi Li, Gangqiang Xu, and Bei Liu wrote the manuscript.

\section{Conflicts of Interest}

The authors declare no conflict of interest.

\section{References}

1. Chen, Y.F.; Jiang, J.W. A bio-metal-organic framework for highly selective $\mathrm{CO}_{2}$ capture: A molecular simulation study. ChemSusChem 2010, 3, 982-988.

2. Keskin, S.; Liu, J.C.; Rankin, R.B.; Johnson, J.K.; Sholl, D.S. Progress, opportunities, and challenges for applying atomically detailed modeling to molecular adsorption and transport in metal-organic framework materials. Ind. Eng. Chem. Res. 2009, 48, 2355-2371.

3. Mueller, U.; Schubert, M.; Teich, F.; Puetter, H.; Schierle-Arndt, K.; Pastre, J. Metal-organic frameworks-prospective industrial applications. J. Mater. Chem. 2006, 16, 626-636. 
4. Rowsell, J.L.C.; Yaghi, O.M. Strategies for hydrogen storage in metal-organic frameworks. Angew. Chem. Int. Ed. 2005, 44, 4670-4679.

5. Liu, B.; Smit, B. Molecular simulation studies of separation of $\mathrm{CO}_{2} / \mathrm{N}_{2}, \mathrm{CO}_{2} / \mathrm{CH}_{4}$, and $\mathrm{CH}_{4} / \mathrm{N}_{2}$ by ZIFs. J. Phys. Chem. C 2010, 114, 8515-8522.

6. Yang, Q.Y.; Liu, D.H.; Zhong, C.L.; Li, J.R. Development of computational methodologies for metal-organic frameworks and their application in gas separations. Chem. Rev. 2013, 113, 8261-8323.

7. Wu, D.; Yang, Q.Y.; Zhong, C.L.; Liu, D.H.; Huang, H.L.; Zhang, W.J.; Maurin, G. Revealing the structure-property relationships of metal-organic frameworks for $\mathrm{CO}_{2}$ capture from flue gas. Langmuir 2012, 28, 12094-12099.

8. Wu, D.; Wang, C.C.; Liu, B.; Liu, D.H.; Yang, Q.Y.; Zhong, C.L. Large-scale computational screening of metal-organic frameworks for $\mathrm{CH}_{4} / \mathrm{H}_{2}$ separation. AIChE J. 2012, 58, 2078-2084.

9. Zhou, M.; Wang, Q.; Zhang, L.; Liu, Y.C.; Kang, Y. Adsorption sites of hydrogen in zeolitic imidazolate frameworks. J. Phys. Chem. B 2009, 113, 11049-11053.

10. Zhang, K.; Lively, R.P.; Zhang, C.; Koros, W.J.; Chance, R.R. Investigating the intrinsic ethanol/water separation capability of ZIF-8: An adsorption and diffusion study. J. Phys. Chem. C 2013, 117, 7214-7225.

11. Zhang, W.J.; Huang, H.L.; Zhong, C.L.; Liu, D.H. Cooperative effect of temperature and linker functionality on $\mathrm{CO}_{2}$ capture from industrial gas mixtures in metal-organic frameworks: A combined experimental and molecular simulation study. Phys. Chem. Chem. Phys. 2012, 14, 2317-2325.

12. Zhao, Z.X.; Li, Z.; Lin, Y.S. Adsorption and diffusion of carbon dioxide on metal-organic framework (MOF-5). Ind. Eng. Chem. Res. 2009, 48, 10015-10020.

13. Zhao, Z.X.; Ma, X.L.; Kasik, A.; Li, Z.; Lin, Y.S. Gas separation properties of metal organic framework (MOF-5) membranes. Ind. Eng. Chem. Res. 2013, 52, 1102-1108.

14. Keskin, S.; Sholl, D.S. Efficient methods for screening of metal organic framework membranes for gas separations using atomically detailed models. Langmuir 2009, 25, 11786-11795.

15. Keskin, S.; Sholl, D.S. Assessment of a metal-organic framework membrane for gas separations using atomically detailed calculations: $\mathrm{CO}_{2}, \mathrm{CH}_{4}, \mathrm{~N}_{2}, \mathrm{H}_{2}$ mixtures in MOF-5. Ind. Eng. Chem. Res. 2009, 48, 914-922.

16. Keskin, S. Atomistic simulations for adsorption, diffusion, and separation of gas mixtures in zeolite imidazolate frameworks. J. Phys. Chem. C 2011, 115, 800-807.

17. Huang, H.L.; Zhang, W.J.; Liu, D.H.; Liu, B.; Chen, G.J.; Zhong, C.L. Effect of temperature on gas adsorption and separation in ZIF-8: A combined experimental and molecular simulation study. Chem. Eng. Sci. 2011, 66, 6297-6305.

18. Yang, Q.Y.; Wiersum, A.D.; Llewellyn, P.L.; Guillerm, V.; Serred, C.; Maurin, G. Functionalizing porous zirconium terephthalate $\mathrm{UiO}-66(\mathrm{Zr})$ for natural gas upgrading: A computational exploration. Chem. Commun. 2011, 47, 9603-9605.

19. Saha, D.; Deng, S.G. Structural stability of metal organic framework MOF-177. J. Phys. Chem. Lett. 2010, 1, 73-78.

20. Yu, J.M.; Balbuena, P.B. Water effects on postcombustion $\mathrm{CO}_{2}$ capture in Mg-MOF-74. J. Phys. Chem. C 2013, 117, 3383-3388.

21. Saha, D.; Bao, Z.B.; Jia, F.; Deng, S.G. Adsorption of $\mathrm{CO}_{2}, \mathrm{CH}_{4}, \mathrm{~N}_{2} \mathrm{O}$, and $\mathrm{N}_{2}$ on MOF-5, MOF-177, and zeolite 5A. Environ. Sci. Technol. 2010, 44, 1820-1826. 
22. Wehring, M.; Gascon, J.; Dubbeldam, D.; Kapteijn, F.; Snurr, R.Q.; Stallmach, F. Self-diffusion studies in CuBTC by PFG NMR and MD simulations. J. Phys. Chem. C 2010, 114, 10527-10534.

23. Babarao, R.; Jiang, J.W. Unraveling the energetics and dynamics of ibuprofen in mesoporous metal-organic frameworks. J. Phys. Chem. C 2009, 113, 18287-18291.

24. Zhang, K.; Zhang, L.L.; Jiang, J.W. Adsorption of C1-C4 alcohols in zeolitic imidazolate framework-8: Effects of force fields, atomic charges, and framework flexibility. J. Phys. Chem. C 2013, 117, 25628-25635.

25. An, J.; Geib, S.J.; Rosi, N.L. Cation-triggered drug release from a porous zinc-adeninate metal-organic framework. J. Am. Chem. Soc. 2009, 131, 8376-8377.

26. An, J.; Geib, S.J.; Rosi, N.L. High and selective $\mathrm{CO}_{2}$ uptake in a cobalt adeninate metal-organic framework exhibiting pyrimidine- and amino-decorated pores. J. Am. Chem. Soc. 2010, 132, 38-39.

27. Atci, E.; Erucar, I.; Keskin, S. Adsorption and transport of $\mathrm{CH}_{4}, \mathrm{CO}_{2}, \mathrm{H}_{2}$ mixtures in a bio-MOF material from molecular simulations. J. Phys. Chem. C 2011, 115, 6833-6840.

28. Liu, B.; Tang, L.X.; Lian, Y.H.; Li, Z.; Sun, C.Y.; Chen, G.J. Study on separation performance of metal-organic frameworks with interpenetration and mixed-ligand. Acta Chim. Sin. 2013, 71, 920-928.

29. Keskin, S. High $\mathrm{CO}_{2}$ selectivity of a microporous metal-imidazolate framework: A molecular simulation study. Ind. Eng. Chem. Res. 2011, 50, 8230-8236.

30. Ozturk, T.N.; Keskin, S. Predicting gas separation performances of porous coordination networks using atomistic simulations. Ind. Eng. Chem. Res. 2013, 52, 17627-17639.

31. Erucar, I.; Keskin, S. High $\mathrm{CO}_{2}$ selectivity of an amine-functionalized metal organic framework in adsorption-based and membrane-based gas separations. Ind. Eng. Chem. Res. 2013, 52, 3462-3472.

32. Keskin, S. Molecular simulation study of $\mathrm{CH}_{4} / \mathrm{H}_{2}$ mixture separations using metal organic framework membranes and composites. J. Phys. Chem. C 2010, 114, 13047-13054.

33. Krishna, R.; van Baten, J.M. In silico screening of zeolite membranes for $\mathrm{CO}_{2}$ capture. J. Membr. Sci. 2010, 360, 323-333.

34. Gupta, K.M.; Chen, Y.F.; Hu, Z.Q.; Jiang, J.W. Metal-organic framework supported ionic liquid membranes for $\mathrm{CO}_{2}$ capture: Anion effects. Phys. Chem. Chem. Phys. 2012, 14, 5785-5794.

35. Gupta, K.M.; Chen, Y.F.; Jiang, J.W. Ionic liquid membranes supported by hydrophobic and hydrophilic metal-organic frameworks for $\mathrm{CO}_{2}$ capture. J. Phys. Chem. C 2013, 117, 5792-5799.

36. Potoff, J.J.; Siepmann, J.I. Vapor-liquid equilibria of mixtures containing alkanes, carbon dioxide, and nitrogen. AIChE J. 2001, 47, 1676-1682.

37. Rappe, A.K.; Casewit, C.J.; Colwell, K.S.; Goddard, W.A., III; Skiff, W.M. UFF, a full periodic table force field for molecular mechanics and molecular dynamics simulations. J. Am. Chem. Soc. 1992, 114, 10024-10035.

38. Ewald, P.P. Die berechnung optischer und elektrostatischer gitterpotentiale. Ann. Phys. 1921, 369, 253-287.

39. Frenkel, D.; Smit, B. Understanding Molecular Simulation: From Algorithms to Applications, 2nd ed.; Academic Press: San Diego, CA, USA, 2002.

(C) 2015 by the authors; licensee MDPI, Basel, Switzerland. This article is an open access article distributed under the terms and conditions of the Creative Commons Attribution license (http://creativecommons.org/licenses/by/4.0/). 